\title{
Information Graphics Design Challenges and Workflow Management
}

\section{Marco Giardina, University of Neuchâtel, Switzerland, Pablo Medina, Sensiel Research, Switzerland}

\begin{abstract}
Infographics, though still in its infancy in the digital world, may offer an opportunity for media companies to enhance their business processes and value creation activities. This paper describes research about the influence of infographics production and dissemination on media companies' workflow management. Drawing on infographics examples from New York Times print and online version, this contribution empirically explores the evolution from static to interactive multimedia infographics, the possibilities and design challenges of this journalistic emerging field and its impact on media companies' activities in relation to technology changes and media-use patterns. Findings highlight some explorative ideas about the required workflow and journalism activities for a successful inception of infographics into online news dissemination practices of media companies. Conclusions suggest that delivering infographics represents a yet not fully tapped opportunity for media companies, but its successful inception on news production routines requires skilled professionals in audiovisual journalism and revised business models.
\end{abstract}

Keywords: newspapers, visual communication, infographics, digital media technology 
During this time of unprecedented change in journalism, media practitioners and scholars find themselves mired in a new debate on the storytelling potential of data visualization narratives. News organization including the New York Times, Washington Post and The Guardian are at the fore of innovation and experimentation and regularly incorporate dynamic graphics into their journalism products (Segel, 2011). There are at least three reasons why research on infographics deserves so much attention. First, the increasing diffusion of narrative visualizations in the 21st century media ecosystem; as Segel (2011) has noted " politicians, activists, and television reporters use interactive visualizations as a backdrop for stories about global health and economics (Gapminder, 2010) and election results (Farhi, 2008)".

The second argument is related to the key role of visual designers in $21^{\text {st }}$ century newsrooms and their required and ever changing skills. Segel (2011), exploring the proliferation of digital data, notes "visualization designers are melding the skills of computer science, statistics, artistic design and storytelling". A third reason to emphasize infographics research activities is the evolution from static to interactive infographics that has occurred in the last decade.

Static visualization narratives, where graphics, charts, maps and texts are mixed to empower the storytelling process have long existed. In static visualizations, the text conveys the story, and the image typically provides evidence or related details (Segel, 2011). The development of Internet and Web 2.0 and the implementation of an informational culture more based on interactive elements are decisive drivers for an emerging class of visualizations that attempts to combine narratives with interactive graphics.

Data-journalists and digital storytellers are increasingly integrating complex visualizations into their narratives. But crafting successful "data stories" requires a diverse set of skills. Gershon and Page (2001) note that effective storytelling "require[s] skills like those familiar to movie directors, beyond a technical expert's knowledge of computer engineering and science." Segel (2011) continues "while techniques from oration, prose, comic books, video games, and film production are applicable to narrative visualization, we should also expect this emerging medium to possess unique attributes". 
Interactive infographics differ in important ways from stories in text and film as, instead of presenting a tightly controlled and linear progression of events, they invite verification, alternative explanation in a non-linear narrative. Currently, visualization tools have matured and they are enabling the publication of dynamic graphics with variably constrained levels of interactivity and user engagement.

It remains an open question: how infographics production and dissemination challenges datastories design and workflow management routines? To answer this question, this paper, firstly reviews related work on the role of infographics in modern journalism; secondly, it unveils the impact of interactive infographics on information graphics production and dissemination for news organizations; finally, drawing on an empirical case study about the evolution of infographics of New York Times (NYT) in last ten years (2001-2011), it highlights design challenges and workflow management strategies.

\section{Theoretical Framework}

In recent years, at least three decisive drivers have influenced news reporting activities: a) the new information and communication technologies impact on the journalism profession (Bardoel \& Deuze, 2001); b) the increased dissemination of visual (Sturken \& Cartwright, 2001) and interactive (Deighton, Kornfeld, \& School, 2008) digital services; and c) the role of citizen as an active and decisive agent on the news breaking process (Allan, 2009; Sambrook, 2005; Singer et al., 2011). Recent studies (Paterson, 2008) about technological changes in newsrooms have studied how variables such as newsrooms structures, news routines, journalists profiles and their relation with the sources affect the selection and framing of news stories. These research approaches have fruitfully advocated the revitalization of ethnographic methodologies while simultaneously exploring new theoretical frameworks to better understand the evolution of online journalism and how newsroom deal with innovation and change.

In the framework of online journalism innovation, interactive visualization techniques are increasingly being adopted by news organizations. However the design challenges and the impact on newspaper workflow management routines have not been explored in literature. The central proposition of this article is that, the next step for journalism studies in order to understand the potential of interactive visualization techniques to effectively support 
reporter's storytelling process, is to put emphasis on news construction research (Mierzejewska, 2010).

\section{Infographics}

Several studies have analyzed infographics for its plasticity to adapt to different visual formats (Lallana, 1999) while adhering to quality criteria such as clarity, aesthetics, use of linguistic and temporary concordance (Sancho Valero, 2001) and stressed that infographics allow newspapers to optimize the understanding processes thanks to compressed quantity of information and a greater precision, anchored in image and text (Minervini, 2005). Recent infographics researches have put emphasis on the problem of recognizing infographics (Huang \& Tan, 2007) arguing that understanding infographics is a discourse-level problem while others have explored the intersection between infographics and games (Diakopoulos, Kivran-Swaine, \& Naaman, 2011).

In the search for newspaper adequate business models, media scholars (Schroeder, 2004) have argued that interactive infographics can be classified as added values that online mass media can offer to distinguish from conventional media services counterparts. In a survey on interactive infographics added value to online mass media in Europe, Schroeder (2004: 563) has noted:

\footnotetext{
"After more than a decade in existence, online mass media in Europe still face serious economic challenges, accompanied by a paradox: on the one hand, a growing number of Internet users choose online media as their first source of information; on the other hand, most of thoseusers are not willing to pay for the content. Although banner advertisements and other online advertising instruments are increasing at significant rates, they still represent a small portion of the overall advertising market. As a consequence only a few news sites are profitable. The industry and researchers worldwide continually search for adequate business models. One key issue seems to be that online mass media must offer content or services that their conventional counterparts cannot provide. These assets are referred to as added values. Interactive info graphics can be classified as such added values."
} 
Valero (2000) has defined infographic as:

" an informational contribution, developed in written newspapers, done with iconic and typographical elements, that allows or facilitates the understanding of current events, actions or things, or some of its significant aspects, and accompanies or replaces informational text."

The adoption of infographics in modern journalism poses its foundation on a strong pedagogical approach with the main objective of facilitating the understanding of the news drawing on visual culture elements (Franco Álvarez, 2005; Sturken \& Cartwright, 2001). Steve Duenes, graphic director of the New York Times, (NYT, 2008) has argued that 'information graphics should be the right mix of art, journalism and science'. Valero (2010) has noted that stories powered trough infographics allow readers to classify phenomena, highlight trends or demonstrate products.

Although static visualizations crafted with diagrams and charts embedded in larger body of text have been long used in journalism, an emerging class of visualizations, the so called interactive infographics are increasingly integrated by storytellers in their narratives. News organizations including the New York Times, Washington Post and The Guardian regularly incorporate interactive infographics into their journalism (Segel \& Heer, 2010). Interactive infographic can help newspapers to add value and to enhance the quality of their informational product and therefore has a pivotal function on the influence and credibility of newspaper company (Meyer, 2004).

One of the changes that infographic have posed to newspaper is the creation of a departmental structure formed by data visualization, illustrators and journalism professionals. Although technological changes have led many people with different professional profiles to become designers in newspapers (Urbanski \& Miller, 2010), in the framework of infographic production and dissemination, newspapers need very specific professional profiles. Scholarly studies have attempted to capture the core skills required from professionals that devote their journalistic activity to infographic powered journalism. Pablos (1999) have described the infographist as a creative person, with good sense and aptitude for drawing and for synthesizing ideas and emphasized that an effective infographist needs a direct contact with events about which he reports (Pablos \& Manuel, 1999). Framing a specific, unique and well- 
confined infographist professional profile is hard, if at all possible, as journalists need to become professionals with a great flexibility and adaptability competency that allow them a global cross-platform content production (Weiss \& Joyce, 2009). Newspapers need invest time and resources for creating high-quality products specifically designed for online format, and give more support to journalists who create these online products (Busswood, 2010). However, changes entailed to interactive infographics adoption do not refer exclusively to the creation of an infographic department. News organizations must also a) internally adapt their newsrooms work style to the new visual culture promulgated by infographic, and b) externally support their readers to develop a greater visual culture (Cortés \& Sánchez, 2008). In the remainder, we will shed some light on how the evolution of infographic in the last decade is affecting newspaper news design routines and workflow management.

\section{Research Questions}

Considering the literature briefly discussed above, the following research questions are addressed:

RQ1: How infographic has evolved in the last decade?

RQ1a: Which is the news category most covered in infographic news reporting?

RQ1b: Which are the most used multimedia elements in an infographic?

RQ2: Which are the design challenges of infographic powered news reporting?

RQ2a: What are the most used tools for infographic production?

RQ2b: Are standard design workflow used for infographic production?

RQ3: How newspapers workflow management is impacted by the infographic department production and dissemination activities?

RQ3a: Which are the core skills of a journalist involved on a typical infographics design?

\section{Methodology}

To answer RQ1 and the related sub questions we performed a content analysis on a selection of infographics disseminated from The New York Times in the last decade. To answer RQ2, RQ3 and related sub questions we relied on non-structured interviews publicly available on 
the Web and on text (NYT, 2008) and video format ${ }^{1}$ with the NYT graphic editor and most of the infographic department staff members.

Newspapers characteristics have been traditionally studied using content analysis as a common quantitative approach (Boyle, 2012), with emphasis on news and editorial content (Riffe \& Freitag, 1997). Krippendorff (2004: 21) has argued that content analysis can be defined as "'a research technique for making replicable and valid inferences from data to their context'". Content analysis has been fruitfully used when it is hard to structure the material under study, such as a newspapers' stories, because it has been previously created, and distinguishes itself for its capacity of giving an empirical starting point for producing new research evidence about the nature and effect of specific messages (Kolbe \& Burnett, 1991; Krippendorff, 2004). The assets of content analysis are that it is objective, systematic, and quantitative (Kassarjian, 1977; Kolbe \& Burnett, 1991). As our research focus was centered on how infographic has evolved in the last decade and why it could represent an added value for the newspapers value proposition we selected the case study as research method (Yin, 2009) combined with content analysis. More specifically the goal of this study is to analyze the process of employing data-driven journalism on both newspapers printed and digital (Web) forms and to highlight the influence of infographics production and dissemination on media companies' workflow management. Through a content analysis of categories, sources, interactive elements and genres of visualization narratives used in the infographics creation, the process of infographic production can be evaluated.

\section{Data Gathering}

For the purpose of exploring how infographics has evolved in the last decade and to extrapolate the core design challenges and newspaper workflow implications, we collected infographics produced by the New York Times in the decade 2001-2011 and then identified and categorized the evolution from static to interactive multimedia infographics and the possibilities of this emerging news dissemination field. The main criteria used for the selection were the reported categories, content sources, the number of people involved in the

\footnotetext{
${ }^{1}$ Sources: "Steve Duenes tell us how graphic we can be"': http://www.youtube.com/watch?v=p4-_NPxJ-LU; ", Video interview with New York Times' Amanda Cox ': http://www.innovativeinteractivity.com/2010/11/21/new-media-days-amanda-cox-interview/ and .http://infosthetics.com/archives/2011/12/amanda_cox_talks_about_developing_infographics_at_the_new_york _times_graphics.html, retrieved on 11 Nov. 2011;
} 
infographic production, the structure of the infographic formatting both in print and within the Web page, the multimedia as well as social media elements. The rationale behind the selection of New York Times (NYT) infographics lies in the fact that the NYT has invested heavily in experimenting design practices related to infographics production and dissemination. As of 2011 the NYT infographics department employed 25 highly specialized journalists ${ }^{2}$ who research and create diagrams, maps and charts for the newspaper and the Web site. NYT infographics have been featured by scholars (Segel \& Heer, 2010), media and represent arguably the state-of-the-art of what can be achieved today from technologies, tools and newspaper business process when it comes to infographics.

In the remainder, we report an excerpt of the content analysis drawing on 50 representative infographics to highlight how infographics has evolved in the last decade (ref. Table 2). Our goal is to shed some light on elements related to journalism data visualization content genre, multimedia and social media usage, tools and skills required for infographics production and inception into newspaper digital and printed version.

Table 1 Infographics Selection Criteria

\section{Content Analysis}

Information source (internal/external)

Genre of the visual narrative (Segel, E. and Heer, J. 2010)

Narrative structure and reading order (Segel, E. and Heer, J. 2010)

\section{Multimedia}

Video, Audio, 3D

Interactivity

Social Media

We optimized our collection to include infographics that contained clear sequences of narrative events, a diversity of visualization genres (e.g., flow charts, 2D and 3D maps, graphics, video) and a range interaction strategies (filtering, timelines) and sharing possibilities (Twitter, Linkedin, e-mail). Using these criteria, we sampled from our initial larger pool of over 400 to arrive at 50 resulting infographics.

\section{Results}

\section{Content Analysis}

The analyzed design space that relates each example to a specific criterion observed across the dataset is shown in Tab.1 (ref. Appendix I). The table uses a plus sign (+) to indicate the

\footnotetext{
2 "' Video interview with New York Times' Amanda Cox '": http://www.innovativeinteractivity.com/2010/11/21/new-media-days-amanda-cox-interview/
} 
presence of a particular feature and a minus (-) to indicate its absence; the corresponding cell was left empty when the information related to a particular feature couldn't be retrieved.

We observed a substantial increase in the infographic dissemination of the New York Times in the years 2007-2011 when compared to the previous year 2001-2006.

Some selected examples from the printed version have been included from the dataset to underline the needed coordination between the production and dissemination of printed and online version of the infographic. The sample included $11(22 \%)$ printed and $39(78 \%)$ online infographics. Within the sample $74 \%$ used charts, $48 \%$ maps. Among the online infographics analyzed: 20,51\%,10,26\% and 25,64\% used video, audio and 3D multimedia resources respectively and $87,18 \%$ used some level of interactivity.

Social media and sharing possibilities — Twitter, LinkedIn, e-mail— were observed in 46,15 $\%$ of the digital infographics analyzed however only occurring from 2007 onwards. We do not claim that the analyzed sample is exhaustive, tough the considered classification criteria and interjudge reliability evaluation approaches were chosen to guarantee reproducibility and objectivity of the analysis as evaluating the effectiveness or subjectively assessing the aesthetic value of the infographics was beyond the scope of this study. Business (20\%) and U.S. (18\%) are the most reported news categories (RQ1a) and interactive charts (74\%) are the most used interactive elements (RQ1b).

\section{Content Analysis Reliability}

Variables with $\alpha$ equal or above 0.8 are considered reliable (Krippendorff, 2004). Variables with $\alpha$ between 0.667 and 0.8 are considered reliable only for drawing tentative conclusions (Krippendorff, 2004). High levels of disagreement among judges reveal weaknesses in research methods (Kolbe \& Burnett, 1991). Krippendorff's $\alpha$ measuring intercoder reliability of sources attributes has been equal to 0.847 which means that $84.7 \%$ agreement is what can be expected by chance. Interactive elements reliability index has been calculated with $\alpha$ normal and has been equal to 0.956 that can be considered acceptable. 


\section{Design Challenges and Workflow Management}

Specific data-journalism skills, illustration used techniques and news reporting design flows routines required to master the tools, produce effective infographics and make it part of the newspaper workflow routines represent arguably core characteristics of the infographic production processes. Exploring infographics design challenges and workflow routines should pose its foundation in understanding what infographics really is. Even though Amanda Cox, graphic editor at the New York Times, on the question of what infographics really does has answered " Research and create maps and charts for the newspaper and the Web site"' a more insightful framework of analysis should focus on infographics three main functions:

1. Reveal patterns

2. Provide context

3. Describe relationship

NYT infographics are crafted rigorously relying on these functions which are at the core of both data visualization and illustration journalism. One commonly debated question in the infographics professional world is the difference between data visualization and illustration in news reporting. Amanda Cox, describing how the New York Times have reported the Egypt revolution ${ }^{3}$, has claimed:

"'there is a lot of stuff that I can learn when I just want to play around with lines and points in the data visualization world from the guys on the first page, who have spent their career working in $3 \mathrm{D}$ and are better illustrators[...] The kind of ideas that something goes in the front, something goes in the back. Something is there to provide context and something is there because that's what you care about the most $[\ldots]$ the building are rendered in that style not because is the best Gram can do on deadlines or in terms of details. But there is this idea about some details you want to live out [...] the building doesn't need windows because the windows doesn't matter',

Even if NYT employs 3-D illustrators capable of rendering every last detail, in their infographics production superfluous details are avoided and a clear visual hierarchy is

\footnotetext{
3 " Video interview with New York Times' Amanda Cox " http://www.innovativeinteractivity.com/2010/11/21/new-media-days-amanda-cox-interview/
} 
established. Amanda Cox have noted that the fundamental work of illustrators translate one to one in that of data visualization and has noted that both have to "show a pattern leave the details'. Our findings show that at least three factors influence the infographic department design and workflow routines: a) the available computer graphics tools; b) the infographic department employee's illustration, computer graphics and reporting skills and c) the adopted reporting processes.

As for the tools, although researchers and computer scientists have come out with different tools (Bostock \& Heer, 2009; Heer, Card, \& Landay, 2005) to smoothen the data visualization process according to Matthew Ericson ${ }^{4}$, deputy graphics director at The New York Times, the most used tool is still Adobe Flash and most likely, due to its global reach, it will remain so for the years to come (RQ2a). Furthermore, there are underlying principles that a skilled graphic journalist should follow to maintain high quality journalism standards (Giardina \& Medina, 2011) and multidisciplinary competences (RQ2b) are required as Steve Duenes, graphic editor for the New York Times, has noted:

\begin{abstract}
"an information graphic team should focus on the same clearly defined end result. The competences required are multidisciplinary and related to cartography, statistics, graphic design and journalism. Also other domains of competences are a key element in the NYT infographic department staff. For example, Jonathan Corum, senior editor got his degree in Urban Studies, and Shan Carter, interactive designer, majored in Economics" (NYT, 2008).
\end{abstract}

From educational standpoint knowledge in graphic design, computer programming, statistics, illustration and traditional journalism skills should all be part of the infographic department employee's skillset mix.

\title{
Conclusions
}

This explorative article has shown that business and US reportages are the NYT most covered infographics categories. Furthermore it has shed some ideas on three core characteristics that influence the design and workflow routines of the NYT infographic

\footnotetext{
${ }^{4}$ http://datajournalism.stanford.edu/, retrieved on 11 November 2011
} 
department. First, the development of interactive infographics requires the creation of a dedicated departmental structure in newspapers which can operate autonomously; hiring journalists able to master data-journalism techniques and online tools (online journalists); and establish new workflow routines where interactive digital news dissemination becomes an important communication tool. Second, the content analysis of New York Times infographics confirms that interactive elements constitute the foundation of data visualization powered journalistic activity. Finally, interactive infographics led newspaper readers to actively develop their informational and visual culture trough visual narratives which not necessarily reveal all patterns at glance but mandate some level of interaction and judgment.

The latter constitutes a very important evolution in journalism field. The common thread of these three realities is that interactive infographics are a new storytelling element that led newspapers to innovate in a journalistic context characterized by stagnation and organizational crisis. Interactive infographic dissemination represents an added value for newspapers and deploying an efficient data visualization department is a strategic decision, given its financial and managerial implications. The exploratory analysis reported in this essay constitutes a starting point on research on the impact of interactive infographics on two main news production stakeholders: journalists and newspapers management. However, some limitations of this study may be reported, as for example the lack of accurate financial data, the difficulty to analyze and report in a more precise way the internal working process through journalists who create infographics. Often the infographics department professionals have asked not to quote their confessions, this barrier tough not optimal for the integrity of academic studies is in line with the weaknesses of ethnographic methodology (Domingo, 2003). Future research avenues must consider participatory aspects of interactive infographics and put emphasis on reader perception of news disseminated trough infographics drawing on news production theories (Singer, et al., 2011) and on journalism gatekeeping/gatewatching balance (Bruns, 2005). 


\section{References}

Allan, S. (2009). Citizen journalism: Global perspectives (Vol. 1): Peter Lang Pub Inc.

Bardoel, J., \& Deuze, M. (2001). Network Journalism: converging competences of old and new media professionals. Australian Journalism Review, 23(3), 91-103.

Bostock, M., \& Heer, J. (2009). Protovis: A graphical toolkit for visualization. Visualization and Computer Graphics, IEEE Transactions on, 15(6), 1121-1128.

Boyle, K. D. (2012). Transforming the news: the impact of leadership and organizational fctors on the adoption and use of interactive elements on newspaper web sites.

Bruns, A. (2005). Gatewatching: Collaborative online news production (Vol. 26): Peter Lang Pub Inc.

Busswood, P. (2010). News 2.0: How Newspapers Can Survive By Embracing Technological Innovation. Capilano Undergraduate Review, 1(1), 6.

Cortés, R., \& Sánchez, I. (2008). La Infografía en los medios impresos. Estudio descriptivo de La Infografía en el Diario La Nación. Anuario electrónico de estudios en Comunicación Social" Disertaciones", 1(1).

Deighton, J., Kornfeld, L., \& School, H. B. (2008). Digital interactivity: unanticipated consequences for markets, marketing, and consumers: Harvard Business School.

Diakopoulos, N., Kivran-Swaine, F., \& Naaman, M. (2011). Playable data: Characterizing the design space of game-y infographics.

Domingo, D. (2003). Ethnography for new media studies: a field report of its weaknesses and benefits. Alustus uusmedian tutkimuksen symposiumissa Minnesotan yliopistossa.

Farhi, P. (2008). CNN hits the wall for the election. Retrieved from http://bit.ly/cnn-wall

Franco Álvarez, G. (2005). La infografía periodística. Anroart, Las Palmas de Gran Canaria.

Gapminder. (2010). Gapminder Web page Retrieved 12 March 2012, from http://www.gapminder.org

Gershon, N., \& Page, W. (2001). What storytelling can do for information visualization. Communications of the ACM, 44(8), 31-37.

Giardina, M., \& Medina, P. (2011). Impact of interactive infographics on newspapers business models. Paper presented at the International Conference on Business, Research \& Emerging Markets

in Audiovisual Industry, 2011., Lisbon, Portugal.

Heer, J., Card, S. K., \& Landay, J. A. (2005). Prefuse: a toolkit for interactive information visualization. 
Huang, W., \& Tan, C. L. (2007). A system for understanding imaged infographics and its applications.

Kolbe, R. H., \& Burnett, M. S. (1991). Content-analysis research: An examination of applications with directives for improving research reliability and objectivity. Journal of Consumer Research, 243-250.

Krippendorff, K. (2004). Content analysis: An introduction to its methodology: Sage Publications, Inc.

Lallana, F. (1999). Diseño y color infográfico. Revista Latina de Comunicación Social(13).

Meyer, P. (2004). The influence model and newspaper business. Newspaper Research Journal, 25(1), 66-83.

Mierzejewska, B. I. (2010). Media management theory and practice. Managing Media Work, London: Sage Publications, 13-30.

Minervini, M. A. (2005). La infografía como recurso didáctico. Revista Latina de Comunicación Social(59), 15.

NYT. (2008). Talk to the newsroom: Graphics director steve duenes. New York Times.

Pablos, D., \& Manuel, J. (1999). Infoperiodismo. El periodista como creador de infografía. Madrid, Editorial Síntesis.

Paterson, C. (2008). Making online news: The ethnography of new media production (Vol. 49): Peter Lang Pub Inc.

Riffe, D., \& Freitag, A. (1997). A content analysis of content analyses: Twenty-five years of Journalism Quarterly. Journalism \& Mass Communication Quarterly, 74(3), 515-524.

Sambrook, R. (2005). Citizen Journalism and the BBC. Nieman Reports, 59(4), 12-15.

Schroeder, R. (2004). Interactive Info Graphics in Europe--added value to online mass media: a preliminary survey.

Segel, E., \& Heer, J. (2010). Narrative visualization: Telling stories with data. Visualization and Computer Graphics, IEEE Transactions on, 16(6), 1139-1148.

Singer, J. B., Hermida, A., Domingo, D., Heinonen, A., Paulussen, S., Quandt, T., . . . Vujnovic, M. (2011). Participatory journalism: Wiley Online Library.

Sturken, M., \& Cartwright, L. (2001). Practices of looking: An introduction to visual culture: Oxford University Press Oxford.

Urbanski, S., \& Miller, A. (2010). Online Communities' Impact on the Profession of Newspaper Design. Journal of Electronic Publishing, 13(3).

Valero, S. (2000). La infografía de prensa. Revista Latina de Comunicación Social(30), 10. 
Valero, S. (2001). La infografía: técnicas, análisis y usos periodísticos (Vol. 9): Universitat de València.

Valero, S. (2010). La comunicación de contenidos en la infografía digital. Estudios sobre el mensaje periodístico(16), 469-483.

Weiss, A. S., \& Joyce, V. M. H. (2009). Compressed dimensions in digital media occupations Journalists in transformation. Journalism, 10(5), 587-603.

Yin, R. K. (2009). Case study research: Design and methods (Vol. 5): Sage publications, INC. 


\section{Appendix I: Table 1 Design space analysis of New York Times Infographics (Giardina} \& Medina, 2011)

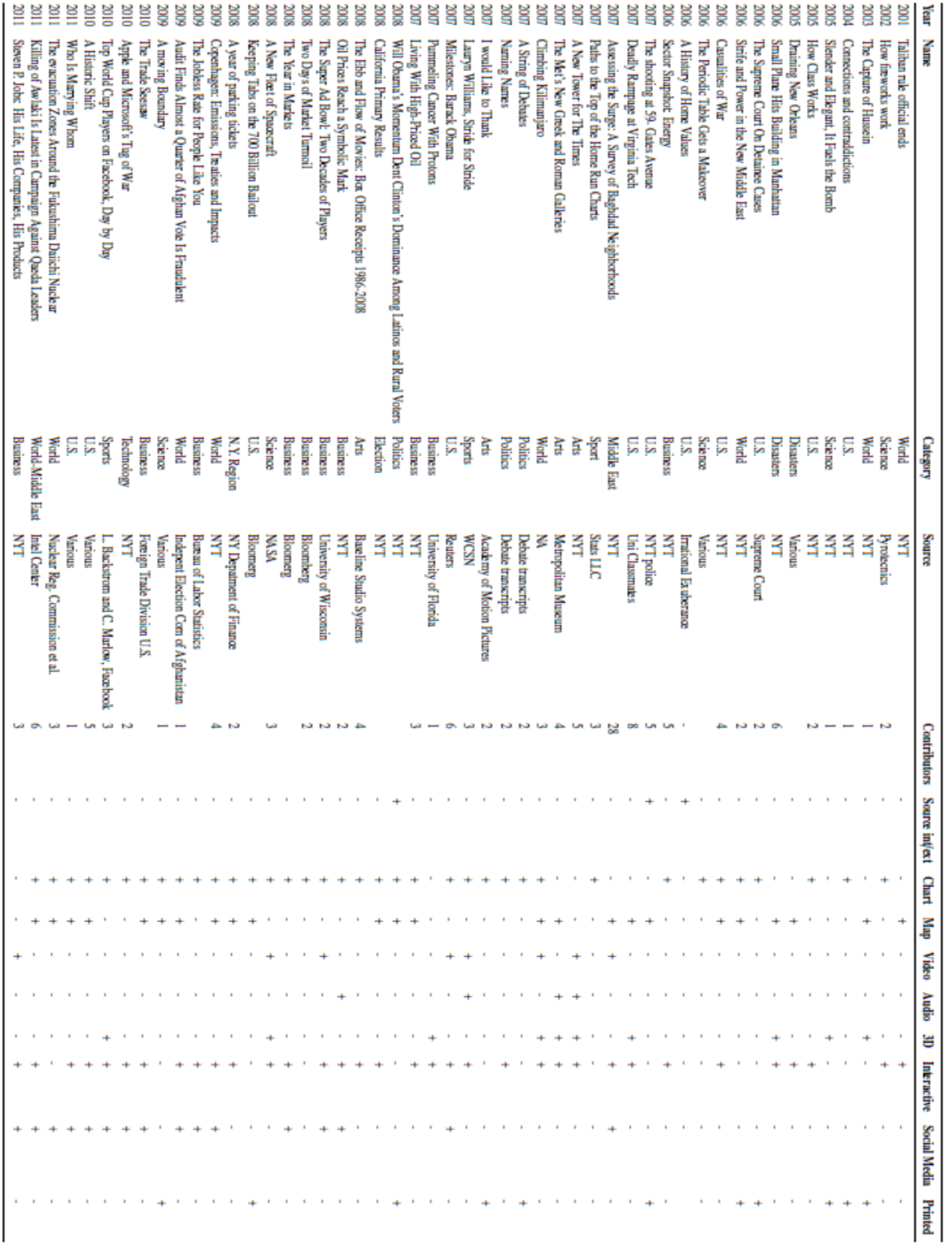


Appendix II: Table 2 News categories covered in infographic news reporting

\begin{tabular}{cc}
\hline Business & $20 \%$ \\
\hline US & $18 \%$ \\
World & $14 \%$ \\
\hline Science & $10 \%$ \\
\hline Politics & $8 \%$ \\
\hline Sports & $6 \%$ \\
\hline Disasters & $4 \%$ \\
\hline Others & $20 \%$
\end{tabular}

